\title{
Sexual cannibalism in the garden spider Araneus diadematus
}

Elgar, Mark A.; Nash, David Richard

Published in:

Animal Behaviour

Publication date:

1988

Document version

Også kaldet Forlagets PDF

Citation for published version (APA):

Elgar, M. A., \& Nash, D. R. (1988). Sexual cannibalism in the garden spider Araneus diadematus. Animal Behaviour, 36, 1511-1517. 
Anim. Behav., 1988, 36, 1511-1517

\title{
Sexual cannibalism in the garden spider Araneus diadematus
}

\author{
MARK A. ELGAR* \& DAVID R. NASH \\ Department of Zoology, University of Oxford, South Parks Road, Oxford OX1 3PS, U.K.
}

\begin{abstract}
In natural populations, courting males of Araneus diadematus are often consumed by females before they have successfully copulated. Despite the possible nutritional benefits of sexual cannibalism for females, the male can derive no benefit by being consumed before copulation. In this study, females that consumed a single male significantly increased their body mass, regardless of the quality of their diet. The implication is that, for $A$. diadematus, sexual cannibalism increases female fecundity. In experimentally controlled courtship sequences, larger males were less likely to be cannibalized than smaller males, but female size had no effect on male mating success. The mating success of males was not influenced by the age of the male, indicating that cannibalism is not the result of male senility.
\end{abstract}

Arachnids are notorious for the predatory nature of their mating and courtship behaviour, and a variety of male adaptations have evolved apparently in response to the rapaciousness of the female. For example, males of the crab spider, Xysticus, throw several lines of silk over the female before attempting to copulate with her, although this does not appreciably inhibit her movements (Bristowe 1958). The jaws of female Tetragnatha orb-weavers are held open with specialized curved spurs on the jaws of the males (Bristowe 1958). Males of several araneid orb-weavers attempt to maie with ecdysing females when cannibalism is physically impossible, while in other species courtship is not initiated by the male until the female is feeding on a prey item (see Robinson 1982 for a review). The nuptial gifts offered by males to the females of the nursery web spider, Pisaura mirabilis, may also be a mechanism for reducing cannibalism (Bristowe 1958) although Austad \& Thornhill (1986) found little supporting evidence for this.

Despite the appeal of sexual cannibalism in the popular literature, no study has recorded more than anecdotal observations of the relative frequency of cannibalism in spiders; for example, cannibalism has been noted in dictynids (Jackson 1979), salticids (Jackson 1980) and araneids (e.g. Robinson \& Robinson 1980). Jackson (1980) reported cannibalism in $1 \%$ of 1834 interactions between courting males and females, although it is not clear how many different individuals this represented. Furthermore, these studies have not

* Present Address: School of Biological Science, University of New South Wales, P.O. Box 1, Kensington, Sydney, N.S.W. 2033, Australia. always indicated whether cannibalism occurs before, during or after copulation.

The evolutionary significance of sexual cannibalism after, or during copulation has been examined theoretically by Buskirk et al. (1984). Their model shows that a male may increase his fitness by being eaten by his mate if the chances of subsequent matings are low, and the nutritional value of his body makes a significant difference to the successful development of his offspring. Thus, under some circumstances, males may be expected to sacrifice their lives after or even during copulation. However, sexual cannibalism in orb-weaving spiders commonly takes place before copulation (e.g. Austin \& Anderson 1978; Robinson \& Robinson 1980) although there are exceptions (see Grasshoff 1964; Blanke 1983). The model proposed by Buskirk et al. (1984) does not apply in this case; while the female may still benefit from a nutritious meal, there is no benefit of this behaviour to the courting male.

Gould (1984) criticized Buskirk et al.'s (1984) model and claimed that while sexual cannibalism with active male complicity may be favoured, it has evolved rarely, if ever. Instead, he argued that the indiscriminate predatory behaviour of females may have evolved for some other reason, and that some males are eaten despite any adaptations to escape (see also Jamieson 1986). Bristowe (1958) and Jones (1983) have suggested that older males are less agile, and that sexual cannibalism is more likely for older males. Other attempts to evaluate the evolutionary significance of sexual cannibalism have focused on its influence on the courtship behaviour of spiders (e.g. Robinson 1982). 
In this paper, we explore the effects of physical and behavioural factors on the ability of males to avoid cannibalism in the garden spider, Araneus diadematus. We also evaluate the consequences of sexual cannibalism for females by establishing whether the consumption of a single male has a significant effect on her body weight and, by implication, her fecundity.

\section{METHODS}

Immature spiders of $A$. diadematus were collected from a large, dense population on the north Norfolk coast, U.K., and placed in individual rearing cages. The cages were housed in an open greenhouse that allowed natural illumination and temperature variation. The spiders were fed on commercially reared green-bottle flies, Lucilia sericata (Calliphoridae) and allowed to mature as adults. To standardize food intake, all females were kept on the same diet of approximately one fly every 2 days prior to the experiment.

\section{Courtship}

The female was placed in a courtship frame $(35 \times 35 \times 10 \mathrm{~cm})$ and allowed to build her orb-web overnight. She was then removed, weighed, and replaced onto her web. A single fly was thrown into the web to assess whether she exhibited usual predatory behaviour. If the female failed to respond to the prey item, or dismantled her web, the courtship sequence was abandoned, otherwise she was allowed to consume the fly.

The male was weighed and then placed at the bottom of the female's courtship frame 15 min after the prey item had been introduced. We noted the time at which he physically located the female's web, built his first mating thread, the female adopted the hanging position and, depending on the outcome, the time until the first and second copulations, or that at which he was captured by the female. We also recorded features of the courtship behaviour of males and females (see below).

The experiment was abandoned if within $1 \mathrm{~h}$ of introduction, the male did not build mating threads, the female failed to respond or the male left the courtship frame without attempting to copulate with the female. Of 91 courtship sequences, 39 were abandoned in this way.

\section{Cannibalism}

A sub-set of the females used in the above experiments were used to evaluate the consequences of sexual cannibalism on the subsequent weight of females under two dietary regimes. Before the courtship experiment, females were randomly assigned to one of four treatments that varied both whether a male was to be consumed and the diet after mating. Females were either allowed, or prevented from consuming a male. After mating, the females were fed on one of two dietary regimes; a diet of one fly per day, or a diet of one fly every 4 days. Females remained on these diets for 36 days, and were then weighed, thus providing information on the nutritional effects of cannibalism of males after copulation has taken place. The average mass of a virgin female was 77 $\mathrm{mg}(\mathrm{SD}=18 \mathrm{mg}, N=39)$, that of a consumed male, $19 \mathrm{mg}$ ( $\mathrm{sD}=4 \mathrm{mg}, N=20$ ) and that of a fly, $22 \mathrm{mg}$ $(\mathrm{SD}=5 \mathrm{mg}, N=20$ ).

If a female captured a male that she was not designated to consume, he was simply removed from her clutches. If the female failed to capture a male designated for cannibalism after copulation, he was chilled in a freezer for a short time to reduce his mobility, and then thrown into her web, where he was immediately wrapped and consumed. This allowed the frequency and conditions of male capture (which would inevitably lead to consumption in field populations) to be measured, while vigorously controlling the actual consumption of males. If a female remained unmated after the courtship sequence, further males were introduced to the mating cage until a successful copulation took place, whilst ensuring that none of these males was eaten.

\section{RESULTS}

\section{Courtship and Copulation}

After moulting, adult males of $A$. diadematus cease to build orb-webs and are therefore unable to forage. However, they may replenish energy needs by eating the silk threads of the webs of females with whom they have been courting, and we have even observed males of $A$. diadematus in natural populations feeding on the prey caught in the webs of other, smaller species of spider.

Before searching for females, the male ejaculates sperm onto a small, silken sperm pad, which is then 
absorbed into his pedipalps through a process of sperm induction (see Foelix 1982). Little is known about the mate-searching behaviour of orb-weaving spiders, but it may be facilitated by female pheromones in some species (see Robinson 1982 for a review).

Courtship and copulation in $A$. diadematus can take up to several hours, and the female may kill and consume the male at any stage during this time. It is important to note that the response of the female towards a male is different from her response towards a prey item. Prey items are ensnared in her orb-web, and she immediately captures and wraps them in silk. In contrast, the male approaches the female along the structural threads of her web, and it is very rare that he will ever venture directly onto the orb-web. Instead, the male constructs a 'mating thread' from the edge of the orb-web to either the vegetation or the structural threads of the female's web. The female, who is positioned at the hub of the orb-web, may orient towards the male and rapidly bounce up and down, violently shaking the web. This behaviour resembles that of a resident female responding to an intruding female that is attempting to usurp her web (Elgar, personal observation).

The male moves along the mating thread, plucking and strumming on it, while still attached to the vegetation with his dragline. The female responds by moving towards the male, although if she is too quick the male drops from the mating thread while still attached to his dragline. He then constructs another mating thread, and eventually the male and female slowly approach each other. Once the female is within reach of the male, he caresses her front legs and body with his long front (I) legs, and she responds by 'hanging' from the mating thread by her III and IV legs, drawing her other legs towards her body (Fig. 1). While the female is hanging in this position, the male makes little 'jumps' up and down on the mating thread, and small 'pseudo-copulations'. Finally, the male embraces the female, and inserts one of his pedipalps. After copulation, the male springs away from the female and hangs by his dragline for several minutes, during which time the female returns to the hub. The male must then repeat the entire courtship sequence in order to insert his other pedipalp. Further details and illustrations of courtship and copulation in $A$. diadematus are described by Gerhardt (1911), Bristowe (1958), Blanke (1983) and Hughes (1986).

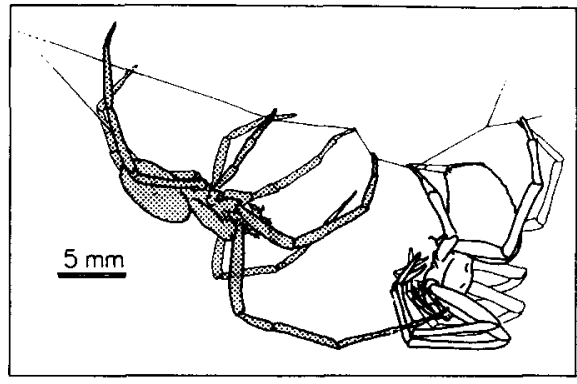

Figure 1. Courtship in $A$. diadematus: the female hangs from the mating thread, supported by her legs III and IV, and the male (shaded) makes 'pseudo-copulations' at her usually without touching. The female is more docile in this position, although she may suddenly lunge at the male and capture him. (Drawing by Nash.)

\section{Mating Success of Males}

The courting male was captured by the female in 21 of the 52 mating experiments, and, of these, $62 \%$ occurred before an insertion took place. Of the males that avoided capture by the female, $68 \%$ made two insertions and $32 \%$ made one insertion and then left without attempting to make a second one (see Table I).

The mating success of a male was significantly affected by his mass, independently of the mass of the female; males that made one or two insertions and avoided cannibalism were heavier than those that were captured by the female (Table I). The mass of the female had no significant effect on male mating success. There was no evidence that older males were more vulnerable to cannibalism than younger males. One-way analysis of variance showed that male age, measured as the number of days since the adult moult, was not associated with male mating success (Table I).

The time from when the male located the female's web to when he made his first pedipalp insertion (total courtship time) was positively correlated with the mass of the female (Spearman rank correlation coefficient $r_{\mathrm{s}}=0.338, N=39$, $P<0.05$ ), but was not significantly correlated with that of the male $\left(r_{\mathrm{s}}=-0 \cdot 182, N=39\right.$, Ns). The mean duration of the first pedipalp insertion was $6 \cdot 3 \mathrm{~s}(\mathrm{SD}=5 \cdot 9, N=39)$, ranging between 2 and $28 \mathrm{~s}$. The mean duration of the second insertion was $7 \cdot 1 \mathrm{~s}$ (SD $=5 \cdot 4, N=21$ ), ranging between 2 and $22 \mathrm{~s}$, and was not significantly different from the duration of the first insertion (paired $t$-test: $t_{\mathrm{s}}=1 \cdot 02, d f=20$, Ns). The duration of the first pedipalp insertion was positively correlated with male size (Fig. 2), but not 
Table I. Determinants of male mating success in $A$. diadematus

\begin{tabular}{lcccccc}
\hline & $\begin{array}{c}\text { No insertion } \\
\text { and eaten }\end{array}$ & $\begin{array}{c}\text { One insertion } \\
\text { and eaten }\end{array}$ & $\begin{array}{c}\text { One insertion } \\
\text { and escaped }\end{array}$ & $\begin{array}{c}\text { Two insertions } \\
\text { and escaped }\end{array}$ & $F$ \\
\hline Courtship sequences & 13 & 8 & 10 & 21 & \\
Male mass (mg) & 17.5 & 17.5 & 20.6 & 23.5 & $8.12^{*}$ \\
& $(3.4)$ & $(1.9)$ & $(3.1)$ & $(5.0)$ & 1.82 \\
Female mass (mg) & 81.9 & 79.1 & 83.7 & 69.9 & $(17.6)$ & 1.68 \\
Male age (days) & $(19.3)$ & $(17.4)$ & $(20.1)$ & 18.9 & \\
& 24.7 & 21.4 & 23.4 & $(7.2)$ & \\
\hline
\end{tabular}

One-way analysis of variance was used to make comparisons among male age. Male and female body mass were compared simultaneously using discriminant analysis (following Nie 1983) for which there was no significant interaction $(F=1.22, P>0.3)$. Values given are means, with standard deviations in parentheses.

$* P<0.001$.

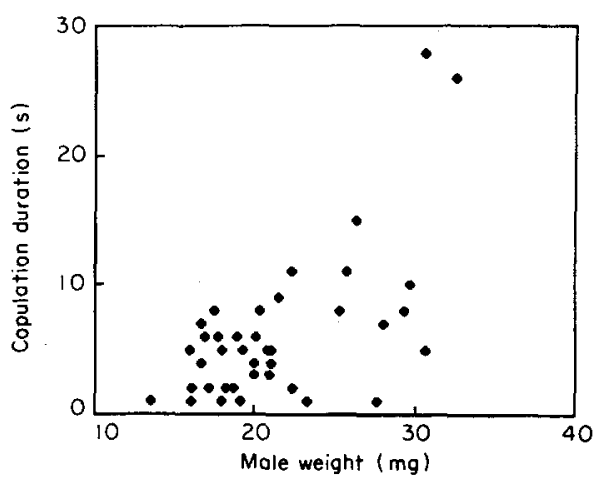

Figure 2. The duration of pedipalp insertion in $A$. diadematus in relation to male body mass $\left(r_{\mathrm{s}}=0 \cdot 613\right.$, $P<0.001, N=39$ ).

with female size $\left(r_{\mathrm{s}}=-0.075, N=39\right.$, NS). There was no significant correlation between the duration of the second pedipalp insertion and either male size $\left(r_{\mathrm{s}}=0.264, N=21, \mathrm{Ns}\right)$, or female size $\left(r_{\mathrm{s}}=-0 \cdot 082, N=21, \mathrm{NS}\right)$.

\section{Courtship and Cannibalism}

The total courtship time of males that made at least one pedipalp insertion $(\bar{X} \pm \mathrm{SD}=24.92 \pm 19 \cdot 7$, $N=39$ ) was not significantly different from that of males that were cannibalized before making any pedipalp insertion $\left(\bar{X}_{ \pm} \mathrm{SD}=39 \cdot 16 \pm 62.8 \mathrm{~min}\right.$, $N=13$; Mann-Whitney $U$-test: $U=251, Z=0.053$, NS).

The lunge rate of females (number of lunges/ courtship time) was not correlated with either male body mass $\left(r_{\mathrm{s}}=0 \cdot 10, N=52\right.$, Ns), male age

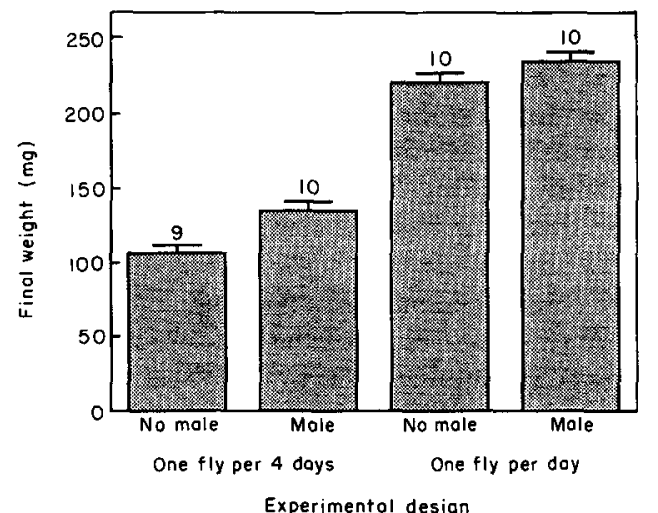

Figure 3. The effects of diet and cannibalism on the final mass of females of $A$. diadematus. Bars represent standard deviations, with sample size written above.

( $\left.r_{\mathrm{s}}=-0 \cdot 28, N=47, \mathrm{Ns}\right)$ or female body mass $\left(r_{\mathrm{s}}=-0 \cdot 26, N=52\right.$, NS). Nor was there any difference in the lunge rates of females that captured the male $(\bar{X} \pm \mathrm{SD}=0 \cdot 14 \pm 0 \cdot 13$ lunges $/ \mathrm{min}$, $N=13$ ) and females that did not capture the male $(\bar{X} \pm \mathrm{SD}=0 \cdot 19 \pm 0 \cdot 15$ lunges $/ \mathrm{min}, N=39 ; U=190$, $Z=1 \cdot 34, \mathrm{Ns})$

The behaviour of males did not covary with male or female body mass. The jump rate (jumps/ courtship time from construction of first mating thread to either pedipalp insertion or capture) was not correlated with either male weight $\left(r_{\mathrm{s}}=0 \cdot 100\right.$, $N=43$, Ns), age $\left(r_{\mathrm{s}}=0 \cdot 10, N=41\right.$, Ns) or female weight $\left(r_{\mathrm{s}}=0 \cdot 15, N=43\right.$, Ns), and there was no difference in the jump rates of males that mated $(\bar{X} \pm \mathrm{SD}=9 \cdot 42 \pm 7.86 \mathrm{jumps} / \mathrm{min}, N=41)$ and males 
that were eaten $(\bar{X} \pm \mathrm{SD}=8.63 \pm 5.52 \mathrm{jumps} / \mathrm{min}$, $N=19 ; \quad U=153, Z=0.64$, Ns). Similarly, the pseudo-copulation rate of males (number of pseudo-copulations/courtship time from when the female first 'hung' from the mating thread to either pedipalp insertion or capture) was not correlated with either male weight $\left(r_{\mathrm{s}}=0 \cdot 134, N=50\right.$, NS), age $\left(r_{\mathrm{s}}=-0 \cdot 29, \quad N=45, \quad \mathrm{Ns}\right)$ or female weight $\left(r_{\mathrm{s}}=-0.07, N=50\right.$, NS). However, the pseudocopulation rate of males that mated $(\bar{X} \pm \mathrm{SD}=$ $2.60 \pm 2.71$ pseudo-copulations $/ \min N=38$ ) was significantly greater than that of males that were eaten $(\bar{X} \pm \mathrm{SD}=1.37 \pm 0.89$ pseudo-copulations/ $\min , N=12 ; U=137, Z=2.07, P<0.05)$.

\section{Consequences of Sexual Cannibalism for Females}

The final mass of the female was significantly affected by both the consumption of a male and the diet after copulation (Fig. 3). Analysis of covariance (following Nie 1983), controlling for initial female mass, showed that females fed on a diet of one fly per day were significantly heavier than those fed on a diet of one fly per 4 days $(F=271 \cdot 7$, $P<0.001$ ), and females that were allowed to consume a male were significantly heavier than those that were prevented from doing so $(F=8.5$, $P<0.01$; see Fig. 3). The implication is that females that consume a male will increase their fecundity, since body mass and fecundity are positively correlated in orb-weaving spiders (e.g. Bristowe 1958; Wise 1979; Rubenstein 1987; F. Vollrath, personal communication) and the females did not moult during the experiment. Interestingly, the interaction term was not significant $(F=1 \cdot 2$, $P>0 \cdot 2$ ), which indicates that the effects of the treatments are additive. Thus, a female that eats a male will significantly increase her body weight, irrespective of her subsequent food intake.

\section{DISCUSSION}

Males of $A$. diadematus are vulnerable to cannibalism at any stage during courtship and copulation. Of 52 experimentally staged matings, $25 \%$ were terminated by the female capturing the male before copulation took place. A further $15 \%$ of the males were captured after making their first insertion. Sexual cannibalism is often reported from field observations (e.g. Bristowe 1958), and we found dead males in the webs of females in natural populations of spiders on the north Norfolk coast.
The general sequence of male and female courtship in $A$. diadematus in the experimental cages is the same as that observed in the field. Thus, sexual cannibalism in $A$. diadematus is unlikely to be due to laboratory conditions, as has been suggested by Liske \& Davis $(1984,1987)$ for sexual cannibalism in praying mantids (Roeder 1935). Sexual cannibalism is not required for successful copulation in $A$. diadematus, as has been suggested for $A$. pallidus (Grasshoff 1964).

The variation in male mating success is associated only with the size of the male; females of any size are more likely to cannibalize smaller males, but the chance of a male being eaten does not depend upon the size of the female. In A. diadematus, sexual cannibalism occurs quite frequently and is predictably determined by the size of the male (cf. Gould 1984; Jamieson 1986). Male age is not associated with male mating success, contradicting the view that cannibalism is the result of male senility (e.g. Bristowe 1958; Jones 1983).

A size advantage for male mating success has been demonstrated in a variety of invertebrates including, for example, dragonflies (Tsubaki \& Ono 1987), butterflies (Elgar \& Pierce, in press), flies (Thornhill 1980; Partridge et al. 1987; Partridge, in press) and several spiders (e.g. Rovner 1968; Christenson \& Goist 1979; Vollrath 1980; Austad 1983; Rubenstein 1987). In these mating systems, the size advantage has arisen through competition among males for access to females. In contrast, one advantage of large size for males of $A$. diadematus lies in their ability to avoid being cannibalized by the female. Larger males also benefit by remaining in copula with females for a longer time. This may increase the probability that the female's eggs are fertilized, since fertilization may be positively correlated with copulation duration (see Austad 1982).

It is not clear why larger males have a mating advantage, although it is probably due to a physical ability of the males (similar perhaps to spider combat behaviour), rather than the females 'allowing' larger males to mate. The courtship behaviour of males and females offers few clues; the lunge rate of females was not influenced by male size, and did not differ between males that were eaten and males that mated. Similarly, there was also no difference in the jump rates of males that mated and those that were eaten. The higher pseudo-copulation rate of males that mated compared with those that were eaten is difficult to interpret, since it is not corre- 
lated with male size. The possibility that females could not distinguish between smaller males and prey items is unlikely because the behaviour of females towards males does not resemble their behaviour towards prey items.

Males of $A$. diadematus are approximately $25 \%$ of the mass of newly eclosed adult females. This degree of dimorphism is curious, given the advantage of a greater body mass in males (but see Greenwood and Adams 1987; Partridge \& Endler 1988). Several factors associated with the behaviour of males that are off the female's web may impose an upper limit to male body mass. For example, smaller males may be less conspicuous to predators, better equipped to move rapidly between webs in search of females or attain early sexual maturity through more rapid development.

Cannibalism in the Chinese praying mantid, Tenodera aridifolia sinensis, is influenced by the nutritional state of the female; females that are deprived of food are more likely to cannibalize their mate than females on a full diet (Liske \& Davis 1987). It is doubtful that females of $A$. diadematus in this study were also responding to food deprivation because all of the females fed on a fly before courtship took place. Furthermore, females that were lighter (and hence may have been food deprived before collection from the field) were not more likely to cannibalize their mate.

It is surprising that the addition of a single male to a month's diet had a significant effect on the body mass of females. The implication is that consumption of males will increase a female's fecundity, since body mass and fecundity are strongly correlated in spiders (e.g. Bristowe 1958; Wise 1979; Rubenstein 1987; F. Vollrath, personal communication), but, more interestingly, it always benefits a female to consume a male, even if she expects a very high food intake. This is because the effects of male cannibalism and post-copulation diet on female body mass are additive, at least within the range of diets used here.

One possible reason for the significant effect of adding a male spider to a female's diet is that a male has all the nutritional requirements necessary for the production of eggs. This is supported by the fact that the average increase in female mass due to consumption of a male was $11.7 \mathrm{mg}$ (taking into account initial female mass), which represents a mass conversion efficiency (mass gain of the female divided by the mass of the male) of some $62 \%$. In contrast, the average mass gain of females from eating each fly is only $4.1 \mathrm{mg}$, which represents a conversion efficiency of $19 \%$.

Another benefit to females of sexual cannibalism is that it may allow them to discriminate between males. Females may expect either to mate with larger males, or to increase their fecundity by attempting to cannibalize courting males. Larger males may be of higher quality; for example, their large size may reflect a greater ability to locate good foraging sites. The sons of females that mate with males that are able to avoid cannibalism may also be better equipped to avoid cannibalism. This form of mate discrimination through sexual cannibalism suggests a novel cost to female choice (see Pomiankowski 1987). Females in low density populations that attempt to consume their mates may run the risk of remaining unmated. Females may thus alter their cannibalistic behaviour according to their encounter rate with males.

\section{ACKNOWLEDGMENTS}

We thank Nick Davies, Charles Godfray, Alan Grafen, Paul Harvey, Mark Pagel, Naomi Pierce, Andrew Read, Dan Rubenstein and Fritz Vollrath for their advice and helpful comments on the manuscript. Mark Elgar was supported by an SERC Post-Doctoral Research Fellowship, and David Nash was supported by an NERC PostGraduate Research Scholarship.

\section{REFERENCES}

Austad, S. N. 1982. First male sperm priority in the bowl and doily spider, Frontinella pyramitela (Walckenaer). Evolution, 36, 777-785.

Austad, S. N. 1983. A game theoretical interpretation of male combat in the bowl and doily spider (Frontinella pyramitela). Anim. Behav., 31, 59-73.

Austad, S. N. \& Thornhill, R. 1986. Female reproductive variation in a nuptial-feeding spider, Pisaura mirabilis. Bull. Br. arachnol. Soc, 7, 48-52.

Austin, A. D. \& Anderson, D. T. 1978. Reproduction and development of the spider Nephila edulis (Koch) (Araneidae: Araneae). Austral. J. Zool., 26, 501-518.

Blanke, R. 1983. Behaviour as an indicator of taxonomic relationships in arachnology. Verh. naturwiss. Ver. Hamburg, 26, 217-226.

Bristowe, W. S. 1958. The World of Spiders. London: Collins.

Buskirk, R. E., Frohlich, C. \& Ross, K. G. 1984. The natural selection of sexual cannibalism. Am. Nat., 123, 612-625.

Christenson, T. E. \& Goist, K. C., Jr. 1979. Costs and 
benefits of male-male competition in the orb-weaving spider Nephila clavipes. Behav. Ecol. Sociobiol., 5, 8792.

Elgar, M. A. \& Pierce, N. E. In press. Mating success and fecundity in an ant-tended lycaenid butterfly. In: Reproductive Success: Studies of Selection, Adaptation and Demography in Contrasting Systems (Ed. by T. H. Clutton-Brock). Chicago: University of Chicago Press.

Foelix, R. F. 1982. Biology of Spiders. Cambridge, Massachusetts: Harvard University Press.

Gerhardt, U. 1911. Studien über die Copulation einheimischer Epeiriden. Zool. Jbk Abt. Syst. Ökol. Geogr. Tiere, 31, 643-666.

Gould, S. J. 1984. Only his wings remained. Nat. Hist., 93 (9), 10-18.

Grasshoff, M. 1964. Die Kreuzspinne Araneus pallidus: ihr Netzbau und ihre Paarungsbiologie. Nat. Mus., 94, 305-314.

Greenwood, P. J. \& Adams, J. 1987. Sexual selection, size dimorphism and a fallacy. Oikos, 48, 106-108.

Hughes, T. 1986. Flowers and Insects. London: Faber \& Faber.

Jackson, R. R. 1979. Comparative studies of Dictyna and Mallos (Araneae: Dictynidae): II. The relationship between courtship, mating aggression and cannibalism in species with different types of social organisation. Rev. Arachnol., 2, 103-122.

Jackson, R. R. 1980. Cannibalism as a factor in the mating strategy of the jumping spider Phidippus johnsoni (Araneae, Salticidae). Bull. Br. arachnol. Sac., 5, 129-133.

Jamieson, I. G. 1986. The functional approach to behavior: is it useful? Am. Nat., 127, 195-208.

Jones, D. 1983. Spiders of Britain and Northern Europe. Feltham: Hamlyn.

Liske, E. \& Davis, W. J. 1984. Sexual behaviour of the Chinese praying mantis. Anim. Behav., 32, 916-918.

Liske, E. \& Davis, W. J. 1987. Courtship and mating behaviour of the Chinese praying mantis, Tenodera aridifolia sinensis. Anim. Behav., 35, 1524-1538.

Nie, N. H. 1983. SPSS Users Guide. Chicago: McGraw Hill.

Partridge, L. In press. Lifetime reproductive success in Drosophila. In: Reproductive Success: Studies of Selec- tion, Adaptation and Demography in Contrasting Systems (Ed. by T. H. Clutton-Brock). Chicago: University of Chicago Press.

Partridge, L. \& Endler, J. A. 1988. Life history constraints on sexual selection. In: Sexual Selection: Testing the Alternatives. Dahlem Workshop Report (ed. by J. W. Bradbury \& M. Andersson), pp. 265-277. Chichester: John Wiley.

Patridge, L., Hoffmann, A. \& Jones, J. S. 1987. Male size and mating success in Drosophila melanogaster and $D$. pseudoobscura under field conditions. Anim. Behav., 35, 468-476.

Pomiankowski, A. 1987. The costs of choice in sexual selection. J. theor. Biol., 128, 195-218.

Robinson, M. H. 1982. Courtship and mating behaviour in spiders. A. Rev. Entomol., 27, 1-20.

Robinson, M. H. \& Robinson, B. 1980. Comparative studies of the courtship and mating behavior of tropical Araneid spiders. Pacific Insects Monogr., 36, 1-218.

Roeder, K. D. 1935. An experimental analysis of the sexual behavior of the praying mantis (Mantis religiosa). Biol. Bull., 69, 203-220.

Rovner, J. S. 1968 . Territoriality in the sheet web spider Linyphia triangularis (Clerck) (Araneae, Linyphiidae). Z. Tierpsychol., 25, 232-242.

Rubenstein, D. I. 1987. Alternative reproductive tactics in the spider Meta segmentata. Behav. Ecol. Sociobiol., 20, 229-237.

Thornhill, R. 1980. Sexual selection within mating swarms of the lovebug Plecia nearctica (Diptera: Bibionidae). Anim. Behav., 28, 405-412.

Tsubaki, Y. \& Ono, T. 1987. Effect of age and body size on the male territorial system of the dragonfly, Nannophya pygmaea Rambur (Odonata: Libellulidae). Anim. Behav., 35, 518-525.

Vollrath, F. 1980. Male body size and fitness in the webbuilding spider Nephila clavipes. Z. Tierpsychol., 53, 61-78.

Wise, D. H. 1979. Effects of an experimental increase in prey abundance upon the reproductive rates of two orb-weaving spider species (Aranea: Araneidae). Oecologia (Berl.), 41, 289-300.

(Received 11 August 1987; revised 14 January 1988; MS. number: 3073) 